\title{
Removal Mechanism of Oxide Layer on the Surface of Sn-0.4Ti Alloy for Quartz Glass Sealing
}

\author{
Wanli Hao ${ }^{1,2}{ }^{\infty}$, Fangzi $\mathrm{Li}^{1}$, Yongbo Ma ${ }^{1}$, Weiguang Zhang ${ }^{1}$ and Liqun Shi ${ }^{2, *}$ \\ 1 Institute of Nuclear Physics and Chemistry, China Academy of Engineering Physics, \\ Mianyang 621900, China; mianli1976@163.com (W.H.); lfazh2000@sina.com (F.L.); \\ mybmail@163.com (Y.M.); 18981172699@189.cn (W.Z.) \\ 2 Institute of Modern Physics, Fudan University, Shanghai 200433, China \\ * Correspondence: lqshi@fudan.edu.cn; Tel.: +86-180-1972-8552
}

Received: 28 April 2020; Accepted: 1 June 2020; Published: 9 June 2020

\begin{abstract}
The oxide layer on the surface of Sn-0.4Ti alloy and its removal mechanism were investigated by coalitional analyses, using XPS and TEM technologies. The results show that a compact $\mathrm{SnO}_{1.65}$ oxide layer of less than $4 \mathrm{~nm}$ in thickness exists on the surface of Sn-0.4Ti alloy. A large number of $\mathrm{TiO}_{2}$ nanoparticles with scale of several to tens of nanometers were grown in Sn-0.4Ti matrix by depleting $\mathrm{SnO}_{1.65}$ while welding at $800{ }^{\circ} \mathrm{C}$. These nanoparticles were adhered to the interfacial layer between $\mathrm{Sn}-0.4 \mathrm{Ti}$ alloy and quartz glass, which was formed by the reaction of $\mathrm{Sn}-0.4 \mathrm{Ti}$ and $\mathrm{SiO}_{2}$ after $\mathrm{SnO}_{1.65}$ removal from the $\mathrm{Sn}-0.4 \mathrm{Ti}$. This work may promote further works on Sn-Ti design to further improve the welding quality between $\mathrm{Sn}-\mathrm{Ti}$ alloy and quartz glass, and also provide a feasible research idea to remove the oxide layer on the surfaces of solders.
\end{abstract}

Keywords: removal mechanism; oxide layer; Sn-0.4Ti alloy; quartz glass

\section{Introduction}

Glass-metal sealing is widely used in the fields of light source, electric vacuum device and solar receiver tube [1]. The matching sealing between some kinds of glasses, such as borosilicate glass, devitrified glass and Kovar alloy (or stainless steel), has been widely studied [1-6]. The sealing between the quartz glass and metal is challenging, because the thermal expansion coefficient of quartz glass is about one order of magnitude lower than that of metals. In a high intensity discharge lamp, the quartz glass tube needs to link with the metal electrode [7]. At present, transition glass sealing and molybdenum foil sealing are common sealing methods, but these methods show some defects, such as low sealing strength, poor hermetic sealing, etc. $[7,8]$. As far as we know, there is no literature about solders used to directly weld quartz glass and metal. Obviously, using solder to weld quartz glass and metal is a simple process, but the solder must stick to quartz glass, and the welding stress cannot break this quartz glass. We have shown that the Sn-Ti alloy with a Ti content of less than $6 \%$ can react with quartz glass at welding temperature to form a compact interfacial layer [9]. Studies on Sn-Ti alloy have been widely reported [10-22], and Sn-Ti alloy has been used to weld sapphire, diamond grits, zirconia or Poly-Crystalline CVD Diamond Plates in recent years [18-22]. However, almost no reports have focused on Sn-Ti alloy for quartz glass-metal welding except for our previous work [9]. Sn-Ti alloy with low Ti content may have many excellent properties, such as low tensile strength ( 13 MPa), low melting point $(\sim 505 \mathrm{~K})$ and good plasticity [23]. All of these properties are beneficial to improve the stability of the welding structure between quartz glass and metal. Reducing the strength of the Sn-Ti alloy by adjusting the Ti content, the welding stress can be reduced to a safe value. It is suggested that $\mathrm{Sn}-\mathrm{Ti}$ alloy is an excellent active solder for quartz glass sealing. However, Sn-Ti alloy with low Ti content is mainly composed of a pure Sn phase [23]. 
A pure Sn surface can generate a compact oxide layer with a thickness of $2 \mathrm{~nm}$ in a week [24]. Thus, a Sn-Ti alloy with a low Ti content can also generate a compact oxide layer, which may dramatically reduce the solder activity. It is interesting to note that the Ti in the alloy may remove the surface oxide layer and promote a reaction between our Sn-0.4Ti alloy and quartz glass. However, the detailed removal mechanism of the surface oxide layer has not been clarified.

The present work aims to investigate the removal mechanism of the surface oxide layer of Sn-0.4Ti alloy by analyzing the oxide layer and the interfacial state between the Sn-0.4Ti alloy and the quartz glass using XPS and TEM technologies.

\section{Materials and Methods}

Sn-0.4Ti alloy was fabricated by smelting pure Sn and Ti metal, and then formed into slices with a thickness of about $0.2 \mathrm{~mm}$ by a rolling process. Considering the actual need of engineering applications for solder, this Sn-0.4Ti sample was kept in a vacuum chamber of 50-100 Pa for one year before welding and testing.

XPS analyses were carried out by an ESCALAB 250Xi X-ray photoelectron spectrometer (XPS) (Thermo fisher scientific, Waltham, MA, USA). The sample was a square Sn-Ti slice with size of $15 \mathrm{~mm}$. Monochromatic diffraction of the $\mathrm{Al}$ target was used with a beam spot of $\Phi 0.5 \mathrm{~mm}$ in the measurement. At first, the sample surface with no Ar ion sputtering was analyzed, then sputtered for $130 \mathrm{~s}$ by Ar ions. Finally, the sputtered surface was analyzed again.

The welding sample for the Sn-0.4Ti alloy and quartz glass was made in the vacuum furnace (Beijing Nanopa Technology Center, Beijing, China) at $800{ }^{\circ} \mathrm{C}$ under a pressure of $<5 \times 10^{-3} \mathrm{~Pa}$. The welding process lasted $10 \mathrm{~min}$. The welded sample was cut by a diamond wheel, then grinded and polished with a $1 \mu \mathrm{m}$ diamond paste. The interfacial structure of the sample was analyzed using a JEOL JEM-2010 UHR (Tokyo, Japan) transmission electron microscope (TEM) operated at $300 \mathrm{kV}$. Specimens for TEM observation were processed to a thickness of about $100 \mathrm{~nm}$ using a focused ion beam (FIB) with a microsampling system (Hitachi FE-2100, Tokyo, Japan) using a Ga ion beam.

\section{Results}

The binding energy of Sn on the surface of the Sn-0.4Ti sample was investigated by X-ray photoelectron spectrometry (XPS). Figure 1a shows that before Ar ion sputtering, Sn 3d2/5 electrons on the sample surface have four binding energies: $484.94 \mathrm{eV}, 486.75 \mathrm{eV}, 493.36 \mathrm{eV}$ and $495.16 \mathrm{eV}$. But only the binding energies of $484.9 \mathrm{eV}$ and $493.40 \mathrm{eV}$ were retained after $\mathrm{Ar}$ ion sputtering for $130 \mathrm{~s}$, as shown in Figure 1b. By comparing the NIST X-ray Photoelectron Spectroscopy Database [25], both binding energies of $484.9 \mathrm{eV}$ and $493.40 \mathrm{eV}$ belong to the Sn element in atomic state, and the other two binding energies, $486.75 \mathrm{eV}$ and $495.16 \mathrm{eV}$, belong to the $\mathrm{Sn}$ element in the $\mathrm{SnO}_{1.65}$ oxide, indicating that the $\mathrm{SnO}_{1.65}$ layer was eliminated completely by Ar ions sputtering for $130 \mathrm{~s}$. It is well known that pure $\mathrm{Sn}$ can generate a dense oxide layer in atmosphere. Our previous work shows that the main phase of this Sn-0.4Ti alloy is pure Sn. Obviously, although the sample was kept in a vacuum of 50 100 Pa, a compact thin $\mathrm{SnO}_{1.65}$ oxide layer was formed on the surface of our Sn-0.4Ti alloy. The fitting on the spectrum further indicates that in all Sn elements detected on the surface of the Sn-0.4Ti alloy without Ar ions sputtering, the $\mathrm{Sn}$ in pure $\mathrm{Sn}$ phase is about $12 \%$, and in $\mathrm{SnO}_{1.65}$ oxide, it is about $88 \%$. As the detecting depths of XPS in inorganic oxides and in metals are about $1.5-4 \mathrm{~nm}$ and $0.5-2 \mathrm{~nm}$, respectively, from the detected $\mathrm{Sn}$ atom coming from under the oxide layer, the thickness of $\mathrm{SnO}_{1.65}$ oxide layer should be less than the XPS detecting range of $4 \mathrm{~nm}$ in oxide. 


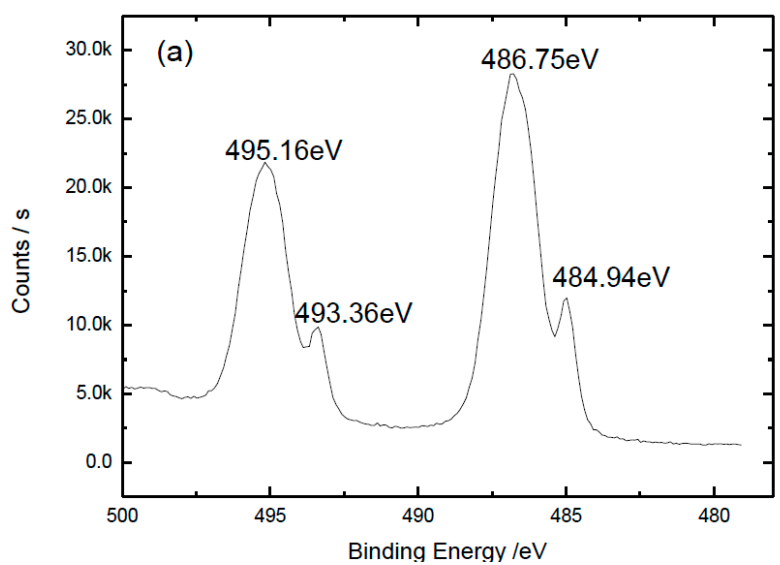

(a)

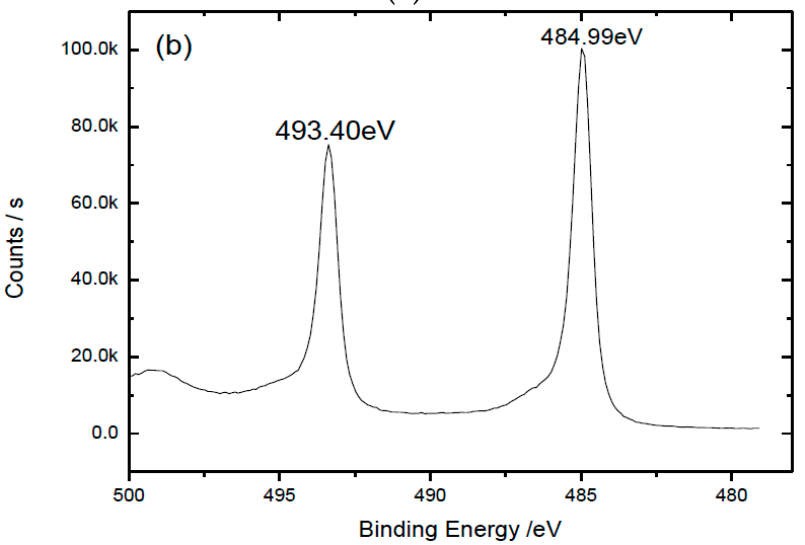

(b)

Figure 1. XPS spectrum of Sn 3d2/5 electrons on Sn-0.4Ti alloy (a) without sputtering; (b) with sputtering for $130 \mathrm{~s}$.

TEM images of the interfacial area between Sn-0.4Ti alloy and quartz glass are shown in Figure 2. In Figure 2a a large number of nanoparticles with a scale of several to tens of nanometers were located in the Sn-0.4Ti matrix. They were connected with the interface layer between the Sn-0.4Ti alloy and quartz glass, which is clearly seen in Figure $2 b$ by a zoomed area containing a single nanoparticle. TEM results show that the thickness of continuous dense interfacial layer is about $20 \mathrm{~nm}$. Some nanoparticles looking like squares are also observed. The side length of the square is up to $\sim 60 \mathrm{~nm}$.

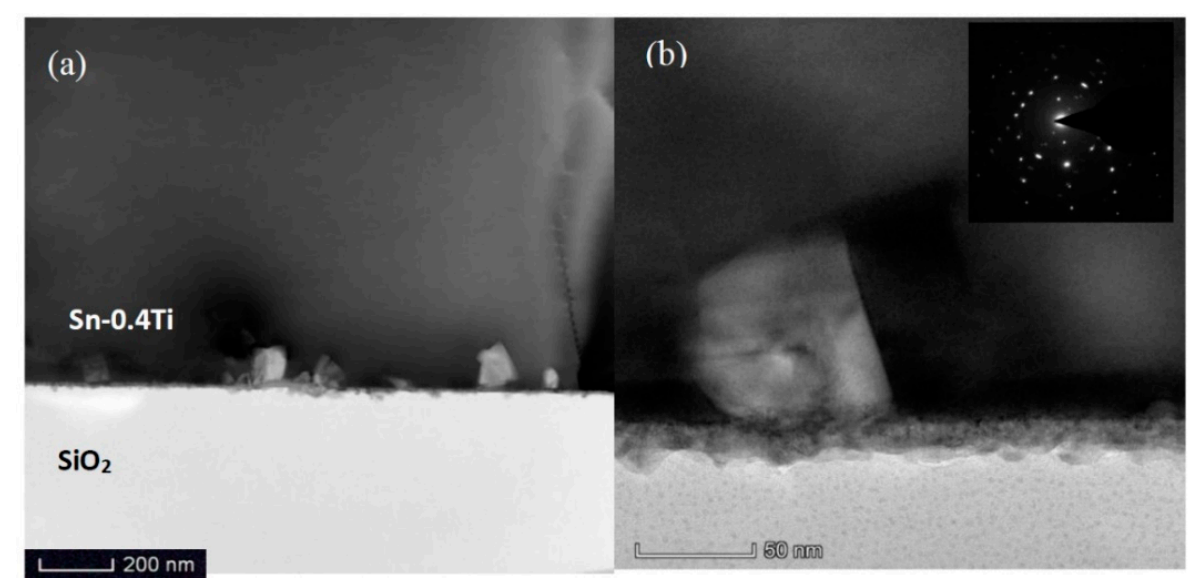

Figure 2. (a,b) TEM images of the interfacial area between Sn-0.4Ti alloy and quartz glass (the insert shows selected area diffraction (SAED) pattern of the $\mathrm{TiO}_{2}$ nanocrystal). 
Figure 3a,b represent the analyzed area and synthetic EDS mapping of all elements. The four possible elements contained in the nanoparticles, $\mathrm{Sn}, \mathrm{Ti}, \mathrm{Si}$ and $\mathrm{O}$, are all scanned and shown in Figure $3 \mathrm{c}-\mathrm{f}$. Only $\mathrm{Ti}$ and $\mathrm{O}$ elements with the atomic ratio of about 1:2 are found in the nanoparticles, indicating that these nanoparticles exist in the form of $\mathrm{TiO}_{2}$. As with the selected area electron diffraction (SAED) pattern shown in the insert of Figure $2 b$, no indication of a diffuse ring, but rather, bright diffraction spots, are observed, suggesting that $\mathrm{TiO}_{2}$ should crystalize in nanoparticles.

In Figure 3e, a thin $\mathrm{TiO}_{2}$ layer between the nanoparticles and $\mathrm{Sn}-0.4 \mathrm{Ti}$ alloy is clearly shown, as reported in the literature [9].

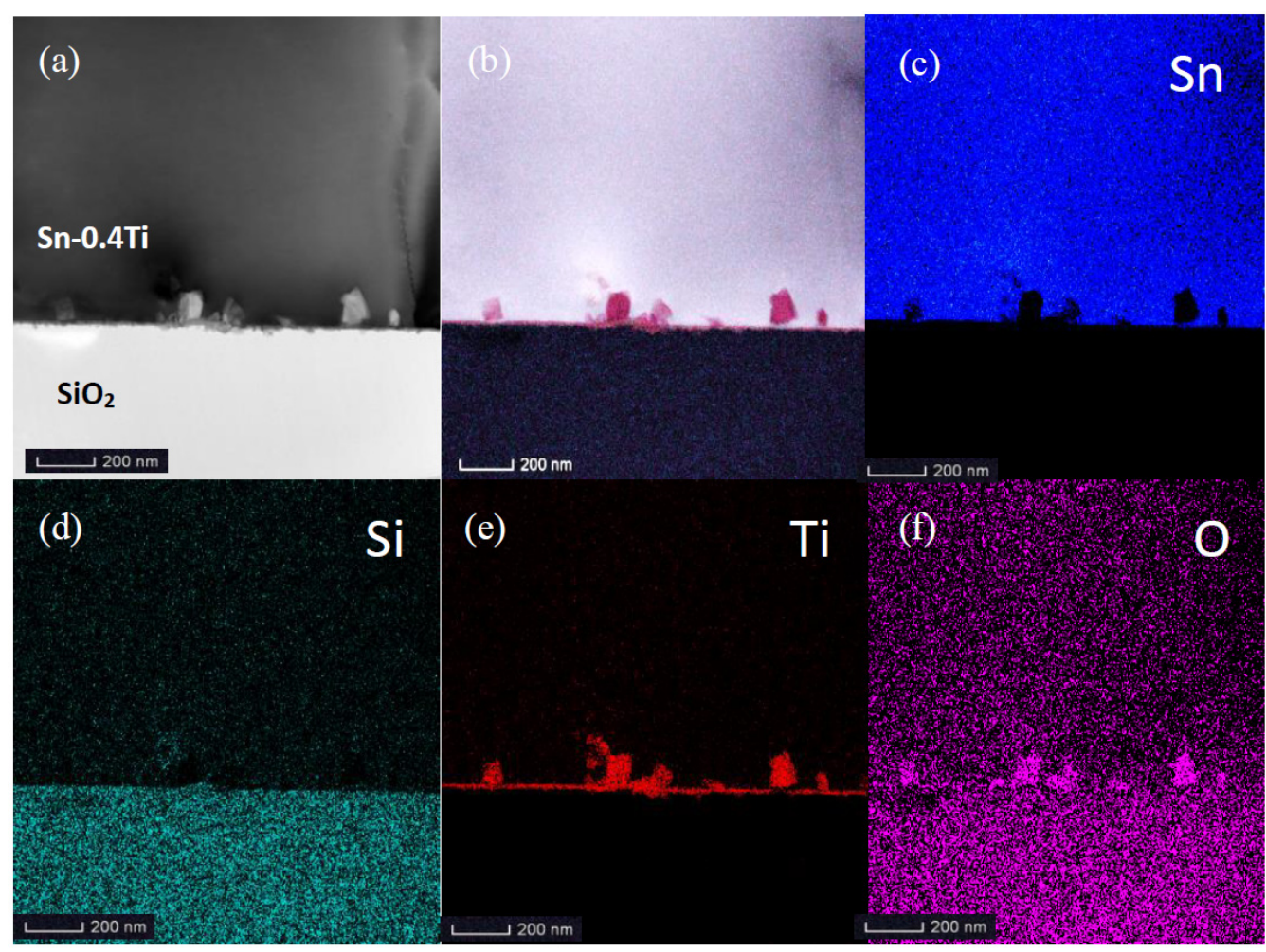

Figure 3. (a-f) EDS mapping of the interface area between Sn-0.4Ti alloy and quartz glass (color online).

\section{Discussion}

As no $\mathrm{TiO}_{2}$ phase exists in the as-received $\mathrm{Sn}-0.4 \mathrm{Ti}$ alloy, the forming mechanisms on $\mathrm{TiO}_{2}$ nanocrystals adhering to the interfacial layer of the $\mathrm{TiO}_{2}$ nanolayer on the $\mathrm{SiO}_{2}$ are put forward. According to our theoretical design of Sn-0.4Ti alloy for quartz glass sealing, the key role of Ti in the alloy is to remove the oxide layer on the alloy surface by its much higher chemical activity than $\mathrm{Sn}$. A displacement reaction between $\mathrm{SnO}_{1.65}$ and $\mathrm{Ti}$ is shown in Equation (1). The thermodynamic calculation shows that the reaction enthalpy $\left(\Delta_{\mathrm{f}} \mathrm{H}\right)$ and the reaction free energy $\left(\Delta_{\mathrm{f}} \mathrm{G}\right)$ are $-315.6 \mathrm{~kJ} / \mathrm{mol}$ and $-317.6 \mathrm{~kJ} / \mathrm{mol}$, respectively, at $25^{\circ} \mathrm{C}$, which clearly means that this reaction is exothermic and spontaneous. Thus, under the welding temperature of $800^{\circ} \mathrm{C}, \mathrm{Sn}-0.4 \mathrm{Ti}$ alloy melts entirely, and Ti atoms diffuse to the surface of oxide layer and react with SnO1.65 according to Equation (1) to generate free $\mathrm{TiO}_{2}$ molecules and $\mathrm{Sn}$ atoms.

Sn atoms will solute in the liquid alloy, while the $\mathrm{TiO}_{2}$ molecules will aggregate into nucleus, growing into nanocrystals in the near surface of liquid $\mathrm{Sn}-0.4 \mathrm{Ti}$ as $\mathrm{TiO}_{2}$ is insoluble in liquid $\mathrm{Sn}-0.4 \mathrm{Ti}$, and the melting point of $\mathrm{TiO}_{2}\left(1850^{\circ} \mathrm{C}\right)$ is far higher than the welding temperature $\left(800^{\circ} \mathrm{C}\right)$. The final size of $\mathrm{TiO}_{2}$ nanocrystals is related to the density of crystal nucleus and the layer thickness of $\mathrm{SnO}_{1.65}$ eliminated by the reaction.

$$
\mathrm{Ti}(\mathrm{L})+\mathrm{SnO}_{1.65}(\mathrm{~S})=0.825 \mathrm{TiO}_{2}(\mathrm{~S})+\mathrm{Sn}(\mathrm{L})
$$


In Figure 4, based on the above analysis, the removal process of the $\mathrm{SnO}_{1.65}$ oxide layer on the surface of Sn-0.4Ti alloy, and the formation of the interface layer, are shown. At room temperature $\left(25^{\circ} \mathrm{C}\right)$, Ti atoms in alloy cannot diffuse out and react with $\mathrm{SnO}_{1.65}$, thus the oxide layer is stable, as shown in (a). When the temperature rises to $800^{\circ} \mathrm{C}, \mathrm{TiO}_{2}$ nanocrystal particles of several to tens of nanometers in size form in the $\mathrm{Sn}-0.4 \mathrm{Ti}$ near the interface, but cannot cover the $\mathrm{SiO}_{2}$, as their dimension is much larger than the thickness of the $\mathrm{SnO}_{1.65}$ layer (b). After the $\mathrm{SnO}_{1.65}$ layer is eliminated completely by Equation (1), fresh Sn-0.4Ti in fusing state could directly contact with quartz glass. Thus Ti atoms diffuse into the $\mathrm{SiO}_{2}$ solid and react with $\mathrm{O}$ to generate $\mathrm{TiO}_{2}$, which finally grow into a thin nano-layered-structure interface $(\mathrm{c}, \mathrm{d})$ connecting $\mathrm{TiO}_{2}$ nanocrystals and $\mathrm{SiO}_{2}$, as reported in our previous work [9].

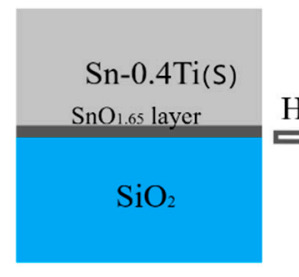

Room temperature

(a)

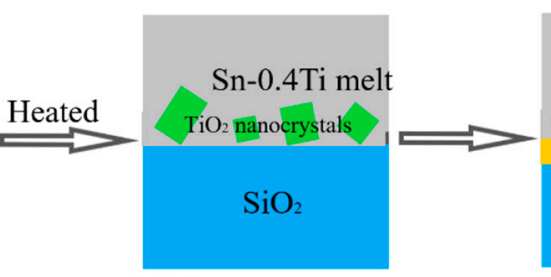

Welding temperature

(b)

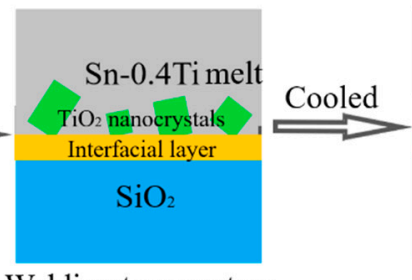

Welding temperature

(c)

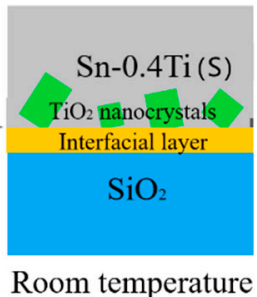

(d)

Figure 4. (a-d) Schematic diagram of the removed mechanism of $\mathrm{SnO}_{1.65}$ layer.

\section{Conclusions}

In summary, the removal mechanism of a $\mathrm{SnO}_{1.65}$ oxide layer was studied in this paper. A compact $\mathrm{SnO}_{1.65}$ oxide layer with a thickness of less than $4 \mathrm{~nm}$ was grown on the surface of the Sn-0.4Ti alloy when it was stored in vacuum of 50 100 Pa for a year. The removal of the $\mathrm{SnO}_{1.65}$ layer is through the reaction between the diffusing $\mathrm{Ti}$ atoms from the liquid $\mathrm{Sn}-0.4 \mathrm{Ti}$ alloy and the $\mathrm{O}$ atoms of $\mathrm{SnO}_{1.65}$ at our welding temperature of $800{ }^{\circ} \mathrm{C}$. The produced $\mathrm{TiO}_{2}$ molecules gather into nuclei growing up to nanoparticles of several to tens of nanometers in dimension in liquate Sn-0.4Ti matrix. These $\mathrm{TiO}_{2}$ nanoparticles adhere to the compact interfacial layer between the Sn-0.4Ti alloy and quartz glass. We hope that the results presented here will promote further works on Sn-Ti design to further improve the welding quality between the Sn-Ti alloy and quartz glass. Because almost all kinds of solders need to remove their oxide layer at welding, the results can also provide a feasible research idea to remove any oxide layer on the surface of solders, especially for similar active solder for different kinds of glass or ceramic sealing.

Author Contributions: Conceptualization and methodology, W.H., L.S., F.L. and Y.M.; writing-original draft preparation, W.H. and Y.M., validation, data curation and formal analysis, F.L., W.H. and W.Z.; investigation, W.H. and Y.M.; writing - review and editing, L.S., F.L., W.H. and W.Z. All authors have read and agreed to the published version of the manuscript.

Funding: This research received no external funding.

Acknowledgments: The authors would like to thank Huahai Shen (Institute of Nuclear Physics and Chemistry, China Academy of Engineering Physics) for their TEM investigation. The support of the Shenyang Institute of Metal Materials, CAS, is greatly acknowledged.

Conflicts of Interest: The authors declare no conflict of interest.

\section{References}

1. Lei, D.; Wang, Z.; Li, J. The analysis of residual stress in glass-to-metal seals for solar receiver tube. Mater. Des. 2010, 31, 1813-1820. [CrossRef]

2. Mantel, M. Effect of double oxide layer on metal-glass sealing. J. Non-Cryst. Solids 2000, 273, 294-301. [CrossRef]

3. Gao, L.; Shen, Z. Influence of A1203 adding on properties of glass bead and wettabilitybetween glass and Kovar alloy. Electron. Compon. Mater. 2011, 30, 52-54. 
4. Chanmuang, C.; Naksata, M.; Chairuangsri, T.; Jain, H.; Lyman, C.E. Microscopy and strength of borosilicate glass-to-Kovar alloy joints. Mater. Sci. Eng. A 2008, 474, 218-224. [CrossRef]

5. Pech, J.; Braccini, M.; Mortensen, A.; Eustathopoulos, N. Wetting, interfacial interactions and sticking in glass/steel systems. Mater. Sci. Eng. A 2004, 384, 117-128. [CrossRef]

6. Widgeon, S.J.; Corral, E.L.; Spilde, M.N.; Loehman, R.E. Glass-to-Metal Seal Interfacial Analysis using Electron Probe Microscopy for Reliable Solid Oxide Fuel Cells. J. Am. Ceram. Soc. 2009, 92, 781-786. [CrossRef]

7. Zhu, S. The Molybdenum Flake of High Strength Gas Discharge Lamp-Siles Seal. Light Light. 2002, 26, 17-18.

8. Xiang, Z.; Wang, Y.; Sui, M. Improvement of Quartz-Tungsten Intermediate Sealing Glass and Research of Sealing Technology. Light Light. 2006, 30, 54-56.

9. Hao, W.; Li, F.; Ma, Y.; Zhang, W.; Shi, L. Nano-layered-structure Interface between Sn-Ti alloy and Quartz glass for hermetic seals. Mater. Lett. 2019, 236, 506-509. [CrossRef]

10. Kuper, C.; Peng, W.Q.; Pisch, A.; Goesmann, F.; Schmid-Fetzer, R. Phase formation and reaction kinetics in the system Ti-Sn. Z. Met. 1998, 89, 855-862.

11. Okamoto, H. Sn-Ti (Tin-Tinium). J. Phase Equilibria Diffus. 2010, 31, 202-203. [CrossRef]

12. Yin, F.; Tedenac, J.; Gascoin, F. Thermodynamic modelling of the Ti-Sn system and calculation of the Co-Ti-Sn system. Calphad 2007, 31, 370-379. [CrossRef]

13. Liu, C.; Klotz, U.E.; Uggowitzer, P.J.; Löffler, J.F. Thermodynamic Assessment of the Sn-Ti System. Mon. Chem. 2005, 136, 1921-1930. [CrossRef]

14. O'Brien, J.W.; Dunlap, R.A.; Dahn, J.R. A Mössbauer effect and X-ray diffraction investigation of Ti-Sn intermetallic compounds: I. Equilibrium phases. J. Alloy. Compd. 2003, 353, 65-73.

15. O’Brien, J.W.; Dunlap, R.A.; Dahn, J.R. A Mössbauer effect and X-ray diffraction investigation of Ti-Sn intermetallic compounds: II. Nanostructured phases prepared by ball milling with $\mathrm{Al}_{2} \mathrm{O}_{3}$. J. Alloy. Compd. 2003, 353, 65-73. [CrossRef]

16. Wang, J.L.; Liu, L.B.; Tuo, B.Y.; Bai, W.M.; Wang, X. Computational Study of Mobilities and Diffusion in Ti-Sn Alloy. J. Phase Equilibria Diffus. 2015, 36, 248-253. [CrossRef]

17. Wang, C.; Luo, Y.; Lu, Y. Measurement of Interdiffusivities and Calculation of Kinetics in bcc Ti-Sn and Ti-Ni Binary Systems. J. Xiamen Univ. 2017, 56, 25-32.

18. Mu, D.; Feng, K.; Lin, Q. Low-temperature wetting of sapphire using Sn-Ti active solder alloys. Ceram. Int. 2019, 45, 22175-22182. [CrossRef]

19. Liao, X.; Mu, D.; Wang, J. Formation of TiC via interface reaction between diamond grits and Sn-Ti alloys at relatively low temperatures. Int. J. Refract. Met. Hard Mater. 2017, 66, 252-257. [CrossRef]

20. Fu, W.; Passerone, A.; Bian, H. Wetting and interfacial behavior of Sn-Ti alloys on zirconia. J. Mater. Sci. 2019, 54, 812-822. [CrossRef]

21. Fu, W.; Song, X.; Passerone, A. Interactions, joining and microstructure of $\mathrm{Sn}-\mathrm{Ti} / \mathrm{ZrO}_{2}$ system. J. Eur. Ceram. Soc. 2019, 39, 1525-1531. [CrossRef]

22. Jiang, L.X.; Qi, H.Q.; Kui, M.D. Wettability of Sn-Ti Alloys on Poly-Crystalline CVD Diamond Plates. Solid State Phenom. 2018, 273, 181-186.

23. Hao, W.; Li, F.; Ma, Y.; Zhang, W.; Shi, L. Microstructure and Properties of Sn-Ti Alloy for quartz glass sealing. Status 2020, manuscript in preparation.

24. Oxide Layer on Common Metal Surface. Available online: https://www.douban.com/note/398604075/ (accessed on 4 December 2019).

25. NIST X-ray Photoelectron Spectroscopy Database. Available online: https://srdata.nist.gov/xps/Default.aspx (accessed on 4 December 2019).

(C) 2020 by the authors. Licensee MDPI, Basel, Switzerland. This article is an open access article distributed under the terms and conditions of the Creative Commons Attribution (CC BY) license (http://creativecommons.org/licenses/by/4.0/). 